\title{
Effect of thinning on surface fluxes in a boreal forest
}

\author{
T. Vesala, ${ }^{1}$ T. Suni, ${ }^{1}$ Ü. Rannik, ${ }^{1}$ P. Keronen, ${ }^{1}$ T. Markkanen, ${ }^{1}$ S. Sevanto, ${ }^{2}$ \\ T. Grönholm, ${ }^{1}$ S. Smolander, ${ }^{1}$ M. Kulmala, ${ }^{1}$ H. Ilvesniemi, ${ }^{3}$ R. Ojansuu, ${ }^{3}$ \\ A. Uotila, ${ }^{4}$ J. Levula, ${ }^{4}$ A. Mäkelä, ${ }^{5}$ J. Pumpanen, ${ }^{5}$ P. Kolari, ${ }^{5}$ L. Kulmala, ${ }^{5}$ \\ N. Altimir, ${ }^{5}$ F. Berninger, ${ }^{6}$ E. Nikinmaa, ${ }^{5}$ and P. Hari $^{5}$ \\ Received 15 June 2004; revised 24 November 2004; accepted 14 January 2005; published 2 April 2005.
}

[1] Thinning is a routine forest management operation that changes tree spacing, number, and size distribution and affects the material flows between vegetation and the atmosphere. Here, using direct micrometeorological ecosystem-scale measurements, we show that in a boreal pine forest, thinning decreases the deposition velocities of fine particles as expected but does not reduce the carbon sink, water vapor flux, or ozone deposition. The thinning decreased the all-sided leaf area index from 8 to 6 , and we suggest that the redistribution of sources and sinks within the ecosystem compensated for this reduction in foliage area. In the case of water vapor and $\mathrm{O}_{3}$, changes in light penetration and among-tree competition seem to increase individual transpiration rates and lead to larger stomatal apertures, thus enhancing also $\mathrm{O}_{3}$ deposition. In the case of $\mathrm{CO}_{2}$, increased ground vegetation assimilation and decreased autotrophic respiration seem to cancel out opposite changes in canopy assimilation and heterotrophic respiration. Current soil-vegetation-atmosphere transfer models should be able to reproduce these observations.

Citation: Vesala, T., et al. (2005), Effect of thinning on surface fluxes in a boreal forest, Global Biogeochem. Cycles, 19, GB2001, doi:10.1029/2004GB002316.

\section{Introduction}

[2] The purpose of thinning is to manage between-tree competition favoring the remaining (often most valuable) trees. After the operation, the growth rate of the remaining trees increases because of higher availability of resources per tree. Thinning is a common silvicultural practice in Scandinavia, central Europe, and Japan, and is gaining increasing popularity in the eastern United States and Canada [Kimmins, 1992]. In Canada the commercial thinnings have increased from about 10,000 ha in early 1990 s to about 25,000 ha in 2000 (http://nfdp.ccfm.org/compendium/ data/2003/tables/com62e.htm). In Finland and Sweden, annual thinnings have been about 300,000 ha during the

\footnotetext{
${ }^{1}$ Department of Physical Sciences, University of Helsinki, Helsinki, Finland.

${ }^{2}$ Biological Laboratory, Harvard University, Cambridge, Massachusetts, USA.

${ }^{3}$ Vantaa Research Centre, Finnish Forest Research Institute, Vantaa, Finland.

${ }^{4}$ Hyytiälä Forestry Field Station, University of Helsinki, Helsinki, Finland.

${ }^{5}$ Department of Forest Ecology, University of Helsinki, Helsinki, Finland.

${ }^{6}$ Département des Sciences Biologiques, Université du Québec à Montréal, Montreal, Quebec, Canada.

Copyright 2005 by the American Geophysical Union. 0886-6236/05/2004GB002316\$12.00
}

last years in both countries [Sevola, 2003] (http:// www.svo.se/fakta/stat/ssi/engelska/).

[3] The opening of the canopy due to the removal of trees results in immediate modifications of the microclimate conditions that influence the primary productivity of trees: The radiation environment and the amount of intercepted rainfall are altered along with wind flow statistics, air temperature, and water vapor deficit (VPD). Delayed changes may occur in soil moisture content and temperature. The remaining trees receive enhanced solar radiation and a larger portion of the available soil water [Black et al., 1980]. The changes in microclimate and soil conditions may, in turn, lead to long-term ecophysiological effects such as changes in the hydraulic transport properties between soil and canopy, increased organic matter decomposition, and, presumably, increased nutrient availability [Piene and Van Cleve, 1978]. Earlier studies on the influence of thinning on surface fluxes have focused on potential changes in soil organic matter [Piene and Van Cleve, 1978], in carbon and water budgets [Black et al., 1980; Whitehead et al., 1984; Aussenac and Granier, 1987; Breda et al., 1995; Van Wijk et al., 2001; Medhurst et al., 2002], and in light interception [Courbaud, 2002]. They have used models or measurements of compartment processes (sap flow, transpiration, foliage $\mathrm{CO}_{2}$ exchange, respiration) and biomass inventories. However, in order to obtain a comprehensive view of the effects of thinning on an entire ecosystem, we need a tool to assess exchange rates for several atmospheric constituents at the whole-ecosystem scale. In recent years, the eddy co- 
variance (EC) technique has emerged as a direct way to determine the whole-ecosystem exchange for some gaseous species [Wesely and Hicks, 2000] and for aerosol particles down to 10-20 $\mathrm{nm}$ in diameter [Buzorius et al., 1998]. Although EC-based estimates of annual budgets of, for example, $\mathrm{CO}_{2}$ exchange may be error prone, $\mathrm{EC}$ measurements can accurately reveal ecosystem responses to environmental factors. Therefore this technique is particularly suited for determining the response of exchange rates of whole ecosystems to environmental perturbations, the relationship between fluxes and phenology, and the factors causing year-to-year variability in fluxes [Baldocchi, 2003].

[4] To our knowledge, earlier studies have not reported the effects of stand thinning on multicomponent surface fluxes using multiyear EC records. Van Wijk et al. [2001] presented pre- and post-thinning results (1 year for each) of EC measurements of $\mathrm{CO}_{2}$ and water vapor fluxes above a Douglas-fir stand, but their main focus was in the interannual variability of the carbon and water budgets modeled with a forest growth/hydrology model. Schade and Goldstein [2003] used a relaxed-eddy-accumulation technique before, during, and after a pre-commercial thinning to measure monoterpene emissions. In addition, Scott et al. [2004] studied changes in the net carbon exchange resulting from shelterwood harvest of a coniferous forest. In our study, the length of the continuous EC flux record before the thinning was 6 years for $\mathrm{CO}_{2}$ and water vapor, $1 \frac{1}{2}$ years for particles, and $1 / 2$ year for $\mathrm{O}_{3}$. We combined these records with measurements of soil respiration and transmitted PAR measurements, a model linking light interception and canopy photosynthesis, and a model of aerosol deposition. Our objectives were (1) to determine the amount by which thinning affects $\mathrm{CO}_{2}$ and water vapor fluxes and $\mathrm{O}_{3}$ and particle deposition and (2) to assess the relative significance of individual processes controlling the observed effects. Our initial hypothesis was that foliage removal would decrease the $\mathrm{CO}_{2}$ sink, transpiration, and $\mathrm{O}_{3}$ and particle deposition rates. As thinning also increases the amount of litter, we expected that enhanced respiration would further decrease the net $\mathrm{CO}_{2}$ exchange.

\section{Materials and Methods}

[5] First, we provide an overview of the measurement site and explain how we estimated the reduction in biomass and leaf area index. Next we describe eddy-covariance (EC) flux measurement, footprint analysis, and data analysis based on comparisons between thinned and intact areas. Finally, we describe the other measurement techniques and models used in this study.

\subsection{Site Description and Thinning}

[6] The SMEAR II station is located in a homogeneous Scots pine stand (Pinus sylvestris L.) planted in 1962 next to the Hyytiälä forest station of the University of Helsinki in southern Finland $\left(61^{\circ} 51^{\prime} \mathrm{N}, 24^{\circ} 17^{\prime} \mathrm{E}, 181 \mathrm{~m}\right.$ above sea level) [see Vesala et al., 1998]. Scots pine is the dominating species in more than half of the forest area in southern Finland. As about one third of southern Finnish forests, the stand in Hyytiälä is of medium site quality (Vaccinium type according to the Cajander site class system [Cajander, 1909]) and

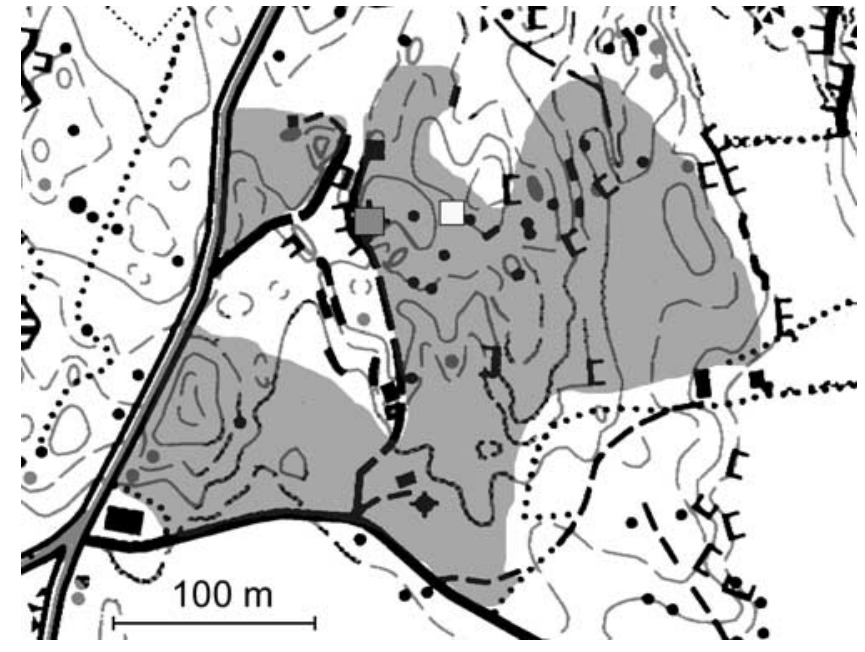

Figure 1. Map of the site. Tower 1 (red square) was installed in April 1996 and measures fluxes of water vapor, $\mathrm{CO}_{2}$, and aerosol particles. Tower 2 (yellow square) was installed in August 2001 and measures fluxes of water vapor, $\mathrm{CO}_{2}$, and $\mathrm{O}_{3}$. The blue areas were thinned JanuaryMarch 2002. See color version of this figure at back of this issue.

has a typical growth rate of $8 \mathrm{~m}^{3} \mathrm{ha}^{-1} \mathrm{yr}^{-1}$. The forest is halfway through the rotation time for this site type. Regeneration and growth of the forest have been performed along standard silvicultural guidelines [Peltola, 2001].

[7] Before the thinning, the height of the dominant stand was around $14 \mathrm{~m}$ and the all-sided needle area was $8 \mathrm{~m}^{2} \mathrm{~m}^{-2}$ (2002). The tree biomass was $68 \mathrm{t} \mathrm{ha}^{-1}$ (aboveground and belowground) [Ilvesniemi and Liu, 2001]. The soil is composed of sandy and coarse silty glacial till. The annual mean temperature in $1961-1990$ was $+2.9^{\circ} \mathrm{C}$, and the annual mean precipitation was $709 \mathrm{~mm}$.

[8] Between January and March 2002, an area of 4.33 ha (Figure 1) was manually thinned according to the forest management guidelines for a first commercial thinning [Forestry Development Centre Tapio, 2001]. The thinning was mainly done from below; that is, most of the removed trees were smaller than average. The first commercial thinning of Scots pine stands in Finland is recommended when a stand reaches an average height of 14 to $16 \mathrm{~m}$. However, if the stand has not previously been tended by precommercial thinning, the average height can be smaller (10$11 \mathrm{~m}$ ). The recommended remaining basal area of trees (i.e., the total of the cross-sectional areas of stems at $1.3-\mathrm{m}$ level) per surface area depends on the height of the dominant trees of the stand and on the quality of the site. For example, at a site of medium fertility, it is recommended to leave a basal area of $14 \mathrm{~m}^{2}$ /ha when the dominant height is $14 \mathrm{~m}$. This corresponds to about 1000-1200 trees/ha.

[9] Biomass inventory measurements in the thinned area show that in this study, the average basal area of the stems at the time of the harvest at the height of $1.3 \mathrm{~m}$ was $24.3 \mathrm{~m}^{2} \mathrm{ha}^{-1}$, and the basal-area-weighed average height was $13.02 \mathrm{~m}$. In the thinning, $6.4 \mathrm{~m}^{2}(=26.4 \%)$ of the basal area was removed.

[10] We calculated the distribution of woody biomass from the measured basal area using allometric functions 
Table 1. Distribution of Biomass Sampling Plots Considered in Relation to Tower $1^{\text {a }}$

\begin{tabular}{cl}
\hline Compass Direction & \multicolumn{1}{c}{ Distance of Plots From Tower 1, m } \\
\hline East & $10,30,50,70,90,110,130,150,170,190$ \\
Southeast & $25,45,65,85,105,125,145,165,185$ \\
\hline
\end{tabular}

${ }^{\mathrm{a}}$ See Figure 1.

[Marklund, 1988], and the all-sided leaf area and biomass using locally determined conversion factors [Palmroth, 2001; Valkeapää, 2001]. The amount of logging residue was calculated as an equal share from the different biomass compartments before thinning that was equal to the proportion of the removed tree basal area. This method introduces a small error in the biomasses due to variation in the tree biomass distribution depending on the competitive position of trees in the stand [Mäkelä and Vanninen, 1998]. The amount of fine roots at the site was estimated earlier in a separate study [Ilvesniemi and Liu, 2001]. An analysis based on 19 sampling plots (Table 1) revealed that the allsided leaf area index (LAI) in the canopy of the thinned areas dropped from 8 to 6 .

\subsection{Eddy Covariance Technique and Flux Variables}

[11] The EC technique is a direct way to determine the exchange rate of a compound across the interface between the atmosphere and a plant canopy. It measures the covariance between fluctuations in vertical wind velocity and fluctuations in compound concentration. Here, wind speed was measured by two sonic anemometers, Solent Research 1012R2 (Tower 1 in Figure 1) and Solent Research 1199HS (Tower 2) (Gill Instruments Ltd., Lymington, Hampshire, England). The concentrations were measured by an infrared absorption gas analyzer Li-6262 (LI-COR Inc., Lincoln, Nebraska), a chemiluminescence gas analyzer LOZ-3 (Unisearch Associates Inc., Concord, Ontario, Canada), and a Condensational Particle Counter (CPC) TSI 3010 (TSI Inc., St. Paul, Minnesota), for $\mathrm{CO}_{2} / \mathrm{H}_{2} \mathrm{O}$ (Towers 1 and 2), $\mathrm{O}_{3}$ (Tower 2), and aerosol particles (Tower 1), respectively. All these measurements were performed at the height of $23 \mathrm{~m}$, approximately $10 \mathrm{~m}$ above the forest canopy. The collected data were quality controlled and corrected for frequency losses and sensor separation in a standard way [Aubinet et al., 2000; Rannik, 1998; Buzorius, 2000]. The $\mathrm{CO}_{2}$ storage term (the accumulation of $\mathrm{CO}_{2}$ ) was estimated by means of concentration profile measurements (at 4, 8, and $17 \mathrm{~m}$ ) using an infrared absorption analyzer (URAS 4, Hartmann and Braun, Frankfurt am Main, Germany). Data collected during low friction velocity $\left(u^{*}\right)$ episodes (below $0.3 \mathrm{~m} / \mathrm{s}$ ) were omitted due to possible underestimation of the fluxes.

[12] In particle flux measurement, we used a 4.5-m-long stainless steel tube (inner diameter $3.6 \mathrm{~mm}$ ) to feed the air from near the anemometer into the CPC, which was located in a box attached to Tower 1 . We used a flow rate of $6.6 \mathrm{~L} \mathrm{~min}^{-1}$ in the sampling tube, $1 \mathrm{~L} \mathrm{~min}^{-1}$ of which passed to the CPC. The cutoff particle diameter (50\% of particles detected) of the particle EC system was experimentally determined to be $14 \mathrm{~nm}$. The first-order response time of the system, including the influence of the $\mathrm{CPC}$ and the damping of concentration fluctuations in the tube, was $0.8 \mathrm{~s}$. Above the Hyytiälä forest, such a frequency response enables the detection of a major fraction of particle fluxes under unstable and near-neutral stratification conditions. More details of the CPC EC system and various aspects of its application and operation, including thorough error analysis, is given by Buzorius et al. [2000].

[13] Because the NEE-based estimate of gross primary production (GPP) is prone to large errors, we used only direct measurements of NEE in the analysis of carbon exchange. Water vapor and ozone fluxes, on the other hand, can be presented in terms of bulk parameters obtained from the measured flux normalized by its main driving force. As such, these bulk parameters represent the contribution of various components to the flux. Thus the water vapor flux $\left(F_{\mathrm{w}}\right)$ can be presented by means of the bulk conductance

$$
g_{\mathrm{b}, \mathrm{w}}=F_{\mathrm{w}} / \mathrm{VPD},
$$

where VPD is water vapor pressure deficit. In dry periods, when there is no evaporation from wet surfaces, $F_{\mathrm{w}}$ represents only transpiration and $g_{\mathrm{b}, \mathrm{w}}$ represents the bulk canopy stomatal conductance, assuming that aerodynamic and quasi-laminar resistances are small [see, e.g., Seinfeld and Pandis, 1998]. As for ozone flux $\left(F_{\mathrm{O} 3}\right)$, the driving force is the concentration difference $c_{\mathrm{i}}-c_{0}$, where $c_{\mathrm{i}}$ is ambient concentration at the measurement level and $c_{0}$ is concentration at the surface. Assuming that $c_{0}=0$, the driving force is simply $c_{\mathrm{i}}$, and $g_{\mathrm{b}, \mathrm{O} 3}$ becomes

$$
g_{\mathrm{b}, \mathrm{O} 3}=F_{\mathrm{O} 3} / c_{\mathrm{O} 3},
$$

which is also, by definition, the deposition velocity of ozone. Again, assuming that that aerodynamic and laminar sublayer resistances are small, $g_{\mathrm{b}, \mathrm{O} 3}$ represents the bulk canopy surface conductance including stomatal and cuticular sinks.

[14] Particle deposition rates are commonly presented by means of the size-dependent deposition velocity $\left(v_{\mathrm{d}}\right)$,

$$
v_{\mathrm{d}}\left(d_{\mathrm{p}}\right)=F_{\mathrm{p}}\left(d_{\mathrm{p}}\right) / N\left(d_{\mathrm{p}}\right),
$$

where $F_{\mathrm{p}}$ is the particle (number) flux and $N$ is the number concentration. Note that the deposition velocity depends strongly on the particle diameter $d_{\mathrm{p}}$.

\subsection{Footprints and Sector Analysis}

[15] The wind directions and areas chosen for the analysis were based on a numerical flux source area (footprint) model [Rannik et al., 2000a; Markkanen et al., 2003]. The model is based on forward simulations of Lagrangian trajectories according to Thomson [1987], and its predictions are comparable with other predictions by similar models. Our model predictions are also in agreement with results from another type of approach based on a boundary layer closure model by Sogachev and Lloyd [2004]. In the most recent model verification by Mölder et al. [2004] based on $\mathrm{SF}_{6}$ tracer experiments the model proved even more reliable. Our footprint model was in good agreement with observations made in Hyytiälä. Oil burning in the forestry station facilities near the 

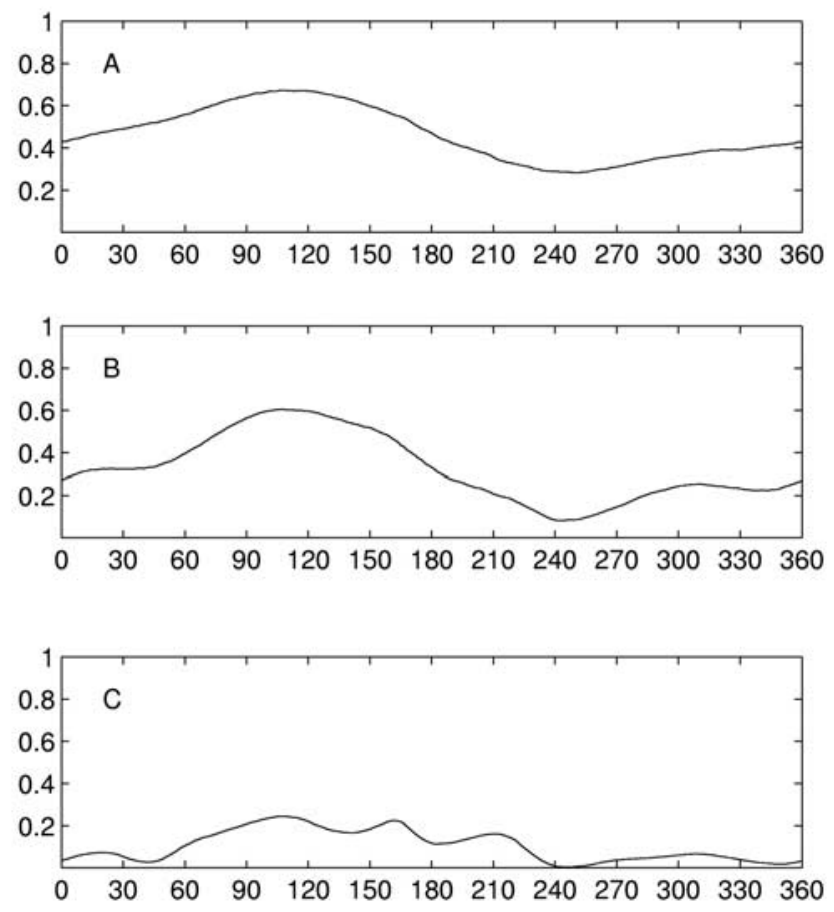

Figure 2. Relative contribution of thinned areas to the footprint as a function of wind direction from Tower 1 under (a) unstable $(\mathrm{H} / \mathrm{L}=-2)$, (b) neutral $\left(\mathrm{H} / \mathrm{L}=10^{-10}\right)$, and (c) stable $(\mathrm{H} / \mathrm{L}=1)$ conditions $(\mathrm{H}=$ height of the canopy; $\mathrm{L}=$ Obukhov length).

Hyytiälä SMEAR II site leads to emission of $\mathrm{CO}_{2}$ in wintertime. In agreement with model predictions, this point source $(600 \mathrm{~m}$ from the tower) was more pronounced in flux measurements made at $46 \mathrm{~m}$ than at $23 \mathrm{~m}$. Furthermore, as the model predicted, a nearby clear-cutting plot (cut in 1997, $300 \mathrm{~m}$ from the tower) was indistinguishable in the 23-m measurements. Finally, according to both the model and observations, a diesel car placed $60 \mathrm{~m}$ upwind from Tower 1 substantially increased the particle flux [Buzorius et al., 2000].

[16] We calculated the 2-D footprint (using $0.85 \times$ [canopy height] as the source/sink height) for 21 cases with atmospheric stratification gradually shifting from unstable to stable $(H / L-2.5$ to +1 , where $H=$ height of the canopy and $L=$ Obukhov length). We then determined the contribution of thinned areas to the measured flux as a function of wind direction for all 21 cases, three of which are shown in Figure 2. Subsequently, we selected wind direction sectors around both towers best representing the thinned areas (thinned areas contributing $>60 \%$ of the flux; hereinafter referred to as $60 \%$ sectors) and the intact areas (thinned areas contributing $<30 \%$ of the flux; hereinafter referred to as $30 \%$ sectors). Because only a part of the stand was thinned and because we had long pre-existing measurement records, we were able to use two independent examination methods. In the first, we compared measurements from the $60 \%$ and $30 \%$ sectors during summer 2002 (spatial comparison), and in the second we compared measurements from the 60\% sectors before (1996-2001) and after (2002) the thinning (temporal comparison). The spatial comparison, based on separation of adjacent thinned and intact sectors, requires high accuracy from footprint estimation both in the radial and in the azimuth directions. Therefore it is more prone to error than the temporal comparison. Note also that no wind direction sectors were purely thinned or purely intact. This masked potential differences in fluxes between the $60 \%$ and $30 \%$ sectors to some extent, but not entirely. For example, if thinning decreases NEE by $25 \%$ and we consider an area of which $60 \%$ is thinned, average NEE will diminish by $15 \%(0.6 \times 0.75+0.4 \times 1=0.85)$. Averaging flux measurements typically reduces random sampling errors to a value within 5\% [Baldocchi, 2003]. Accordingly, the decrease of about $10 \%$ due to thinning should be distinguishable $(0.6 \times 0.9+0.4 \times 1=0.96)$. Finally, part of the northern sector had been thinned in 1993, but no wind direction dependency was distinguishable in 1996 (the starting year of EC measurements) in $\mathrm{CO}_{2}$ and $\mathrm{H}_{2} \mathrm{O}$ fluxes.

\subsection{Multipoint PAR Measurements}

[17] We measured PAR above the ground and field layer (consisting predominantly of lingonberry (Vaccinium vitisidaea), blueberry ( . myrtillus), heather (Calluna vulgaris), and the dominant moss Dicranum polysetum) and above the canopy using a multipoint measuring system. Sets of 24 or 48 radiation sensors were installed in horizontal arrays [Vesala et al., 2000; Palva et al., 2001] approximately $50 \mathrm{~cm}$ above ground. The lengths of the measurement arrays were 4 or $5 \mathrm{~m}$ each, and the distance between adjacent sensors varied from 2 to $20 \mathrm{~cm}$.

[18] We used only cloudy and overcast periods for the analysis in order to minimize the effect of the uneven distribution of the shading elements on light extinction [see Gendron et al., 1998]. Under cloudy conditions, the angular distribution of the incoming radiation is more even than during clear-sky conditions when direct radiation from the direction of the sun disc dominates the measurements. A measurement period was considered cloudy if the measured PAR was less than $50 \%$ of the potential maximum at the respective sun elevation angle.

[19] In July 1999, one sensor array measured in the area that was thinned in 2002. In 2003, after the thinning, altogether three arrays measured in the thinned area and one in the remaining intact part of the site. Four sensors measured the unshaded radiation above the canopy. The averages of simultaneous measurements below the canopy were divided by the above-canopy measurements. The resulting values were finally averaged over time to give estimates for light transmission for thinned and intact canopies. The number of measurement periods (each being $5-20 \mathrm{~s}$ long) used in the analysis was 220,360, and 1620 for measurements in the intact forest in 1999 and 2003 and in the thinned forest in 2003, respectively.

\subsection{Soil Chambers}

[20] We measured soil $\mathrm{CO}_{2}$ efflux several times during 2001 and 2002 with closed chambers and a portable $\mathrm{CO}_{2}$ analyzer (EGM-3, PP Systems, UK). The chamber was 
cylindrical with an internal diameter of $19.4 \mathrm{~cm}$ and a height of $25 \mathrm{~cm}$. A small fan (diameter $2 \mathrm{~cm}$ ) mixed the air inside the chamber during the measurement. For the measurement of $\mathrm{CO}_{2}$ efflux, we set the chamber for $5 \mathrm{~min}$ on a plastic collar (internal diameter $20.4 \mathrm{~cm}$ ) driven $3-4 \mathrm{~cm}$ into the humus. $\mathrm{CO}_{2}$ concentration was recorded at 1-min intervals, and the flux was obtained by linear fitting to five 1-min concentration readings. For respiration measurements, the chamber was covered with aluminum foil to exclude light. Ground vegetation inside the collars was left intact. The measured fluxes thus represented the sum of $\mathrm{CO}_{2}$ efflux from the soil and dark respiration by forest floor vegetation. The number of collars in 2001 was 10, of which three were in the thinned area. All the collars were placed randomly inside the catchment area near the flux tower. The collars were installed on the soil at least 1 year before starting the soil respiration measurements. Seven additional collars were installed in the thinned area in spring 2002, in the immediate vicinity of the original ones. In both the thinned and the intact areas, the distance among the collars was $4-40 \mathrm{~m}$.

\subsection{Aerosol Deposition Model}

[21] The particle concentration detected by the CPC in the EC system is the integral over a size range from coarse particles to fine particles down to about $14 \mathrm{~nm}$ in diameter. Therefore, also the particle flux $\left(F_{\mathrm{p}}\right)$ calculated from the EC measurements represents a large size range of particles. However, because the aerosol particle size distribution and meteorological conditions vary in time, we need to calculate particle $v_{\mathrm{d}}$ as a function of particle diameter $\left(d_{\mathrm{p}}\right)$ and meteorological conditions. Equation (4) shows the relationship among $F_{\mathrm{p}}, v_{\mathrm{d}}$ and $\left(d N / d d_{\mathrm{p}}\right)$,

$$
F_{p}=-\int_{0}^{\infty} \nu_{d} T \frac{d N}{d d_{p}} d d_{p},
$$

where $\nu_{\mathrm{d}}$ is dependent on $d_{\mathrm{p}}$ and $T$ is the particle size transfer function of the EC system (determined experimentally).

[22] Simultaneously with $F_{\mathrm{p}}$, we measured the particle size spectrum at the height of $2 \mathrm{~m}$ (from 3 to $500 \mathrm{~nm}$ particles in diameter) using a Differential Mobility Particle Sizer (DMPS) system [Aalto et al., 2001]. We then used this 2-m spectrum as input for a deposition model based on that of Slinn [1982] and described by Rannik et al. [2003]. The model used the dependence of particle concentration on height and gave as output the particle size spectrum at $23 \mathrm{~m}$ (the EC measurement level). Finally, this $23-\mathrm{m}$ spectrum was fitted to $F_{\mathrm{p}}$ observed at $23 \mathrm{~m}$, and the model produced the average $v_{\mathrm{d}}$ as a function of particle size and meteorological conditions. The prediction of the canopy resistance depends on LAI due to a coefficient of exponential decrease of wind speed inside the canopy [Rannik et al., 2003]. The validity of the estimation of particle size distribution at $23 \mathrm{~m}$ from the measurements at $2 \mathrm{~m}$ is discussed by Rannik et al. [2000b].

\subsection{Model of Light Interception and of Ground- Vegetation and Canopy Photosynthesis}

[23] We calculated tree canopy photosynthesis with the light interception and photosynthesis model of Oker-Blom et al. [1989]. The model treats the canopy as an assembly of individual crowns of specified shape. It accounts both for self-shading due to foliage clumping in the crowns and for shading by other trees, which is calculated using the mean field approximation of Poisson-distributed tree locations. Shoot orientation in crowns was assumed random. Parameters of light extinction and stand structure were estimated for the Hyytiälä stand [Oker-Blom et al., 1989; Ilvesniemi and Liu, 2001].

[24] In order to analyze the effect of thinning on canopy + ground-vegetation photosynthesis, we ran the interception model for a series of LAI values, taking into account the fact that if LAI is reduced through thinning, the crown coverage will also decline. Thus the model allows for comparisons between stands that manifest different levels of clumping of foliage. For example, a natural stand (such as ours before the thinning) would be fairly homogeneous, with crown coverage close to $100 \%$, and would thus have high (LAI-specific) efficiency of photosynthesis. The degree of clumping would be greater after thinning when gaps that cannot utilize the incoming radiation are formed in the canopy. Ignoring this clumping effect when comparing stands of different structures would lead to the underestimation of the difference between photosynthesis before and after thinning.

[25] We estimated the photosynthetic production of the field layer (ground vegetation) with light-response curves fitted to chamber measurements separately for three main species of the ground vegetation, including $V$. myrtillus, $V$. vitis-idaea, and $D$. polysetum. Ground-area-based estimates were obtained using the distributions of the species within the area.

[26] The light response curves are of the following form:

$$
P_{\mathrm{i}}=a_{\mathrm{i}} I /\left(b_{\mathrm{i}}+I\right),
$$

where $P_{\mathrm{i}}$ is the assimilation rate of one of the most dominant plant species $i(V$. myrtillus $(\mathrm{Vm}), V$. vitis-idaea $(\mathrm{Vv})$, and $D$. polysetum (Dp)) and $I$ is PAR in $\mu \mathrm{mol} / \mathrm{m}^{2} \mathrm{~s}$. We determined the parameters $a_{\mathrm{i}}$ and $b_{\mathrm{i}}$ using soil chambers: $a_{\mathrm{Vm}}=0.89$, $a_{\mathrm{Vv}}=0.79, a_{\mathrm{Dp}}=0.86 \mu \mathrm{mol}\left(\mathrm{CO}_{2}\right) \mathrm{m}^{-2} \mathrm{~s}^{-1}$; and $b_{\mathrm{Vm}}=150$, $b_{\mathrm{Vv}}=160$ and $b_{\mathrm{Dp}}=21 \mu \mathrm{mol}\left(\mathrm{CO}_{2}\right) \mathrm{m}^{-2} \mathrm{~s}^{-1}$. We obtained the total ground-vegetation assimilation rate by weighting the individual response functions by a factor of 0.5 for $D$. polysetum and by 0.25 for $V$. myrtillus and $V$. vitis-idaea. Finally, the total ecosystem photosynthesis rate is the sum of canopy and ground-vegetation assimilation.

\section{Results}

\subsection{Microclimate}

[27] We compared the horizontal wind speed under nearneutral conditions (the absolute value of the Obukhov length $L$ being higher than 1000) and observed that the thinning increased the $u^{*}$-normalized wind speed. The difference was statistically significant. The roughness length $z_{0}$ and the displacement height $d$ depend on wind profiles and are sensitive to roughness sublayer correction [see, e.g., Raupach and Thom, 1981]. This complicates their analysis. Since the thinning increased canopy ventilation, it should also have modified temperature and humidity conditions. 

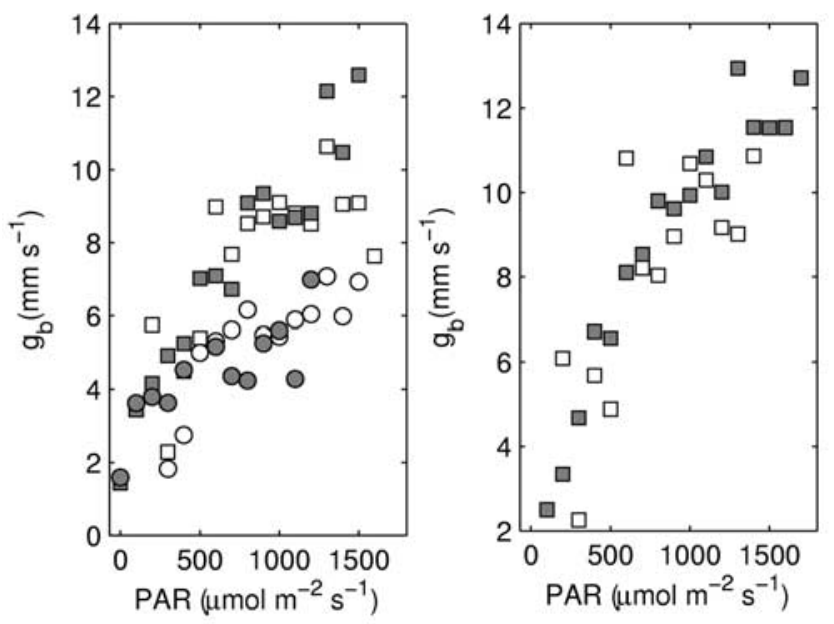

Figure 3. Comparison of the bulk conductance $g_{\mathrm{b}}$ of thinned and intact areas in June-September at RH of $40-$ $70 \%$ as a function of PAR. The $g_{\mathrm{b}}$ was calculated by normalizing measured water vapor and ozone fluxes $\left(F_{\mathrm{w}}\right.$ and $\left.F_{\mathrm{O} 3}\right)$ by vapor pressure deficit and ozone concentration (VPD and $c_{\mathrm{O} 3}$ ), respectively. Wet periods (precipitation events and subsequent 12 hours) were excluded. Each data point represents half-hour measurements averaged over a PAR interval of $100 \mu \mathrm{mol} \mathrm{m}{ }^{-2} \mathrm{~s}^{-1}$ (the average number of half-hour values per data point is $5-28$ ). (left) $F_{\mathrm{w}} / \mathrm{VPD}$ in 2002 for the intact sector (shaded squares, approximately 280 data points) and for the thinned sector (white squares, $231) ; F_{\mathrm{O} 3} / c_{\mathrm{O} 3}$ in 2002 for the intact sector (shaded circles, 181) and for the thinned sector (white circles, 198); (right) $F_{\text {w}} / \mathrm{VPD}$ for the whole south-east sector in 1996-2001 before thinning (shaded squares, 280) and in 2002 after thinning (white squares, 214).

However, the latter two depend also on advection, atmospheric stability, and on $F_{\mathrm{w}}$, and their profiles vary little with height (under near-neutral conditions). When the thinning took place, the forest had a snow cover, and an increase in albedo due to the thinning was distinguishable during the rest of the winter. The albedo increased because the fraction of relatively dark canopy diminished. The average decoupling coefficient $\Omega$ [see McNaughton and Jarvis, 1983] was 0.2 (dry periods from April to September), and the thinning appeared to cause no statistically significant change in it. This value is typical of tall vegetation and indicates high coupling with the atmosphere and thus high stomatal control of transpiration. When $\Omega$ is zero, transpiration is solely related to evaporation imposed by the effects of the air saturation deficit, while when $\Omega$ is 1 , it is obtained from the energy balance for a homogeneous wet surface [see also Waring and Running, 1998]. The decoupling does not explicitly depend on transpiration but on the boundary layer and canopy stomatal conductances.

\subsection{Surface Fluxes}

[28] Figure 3 shows $g_{\mathrm{b}}$ as a function of PAR for RH of 40 to $70 \%$ (wet periods ignored). Neither the spatial nor the temporal comparison indicated any difference between the thinned and intact areas; the stand was evidently neutral to thinning. The results were similar for other RH classes and other months. The difference between the $g_{\mathrm{b}}$ calculated as $F_{\mathrm{w}} / \mathrm{VPD}$ and as $F_{\mathrm{O} 3} / \mathrm{c}_{\mathrm{O} 3}$ at high radiation values (Figure 3 ) arises probably because, in reality, needle temperature $\left(T_{\text {needle }}\right)$ is higher than ambient temperature $\left(T_{\text {ambient }}\right)$, and we use the latter in the calculation of VPD. If, for example, $T_{\text {ambient }}$ is $20^{\circ} \mathrm{C}$ and produces $\mathrm{RH}$ of $50 \%$, we underestimate VPD by $20 \%$ if the real $T_{\text {needle }}$ is $22^{\circ} \mathrm{C}$. In this case, $g_{\mathrm{b}}$ determined from evapo-transpiration measurements (since wet periods were ignored, mainly transpiration) should be multiplied by 0.8 . The $g_{b}$ determined from $\mathrm{O}_{3}$ measurements (Figure 3) is realistic provided that $c_{\mathrm{O} 3}$ within stomata is zero (as normally assumed) and thus not affected by the temperature dependence of its solubility.

[29] Figure 4 presents the relationship between NEE and PAR for three $T_{\text {air }}$ classes $\left(14^{\circ}-17^{\circ} \mathrm{C}, 17^{\circ}-20^{\circ} \mathrm{C}, 20^{\circ}-\right.$ $23^{\circ} \mathrm{C}$ ) in June-July. Again, the stand appeared to be neutral to the thinning. The results were similar for other temperature classes and other months. Figure 5 presents the summertime soil $\mathrm{CO}_{2}$ efflux (sum of soil respiration and dark respiration of the ground vegetation) for the intact and thinned areas. The spatial variation was large and masked the possible effects of thinning. According to multipoint PAR measurements, under overcast conditions the intact and thinned canopies intercepted $87 \%$ and $70 \%$ of the radiation, respectively.

[30] The light not intercepted by the tree canopy was used as input to the field-layer photosynthesis model. The model runs were conducted for typical clear and overcast days in July, when temperature is not limiting $\left(15^{\circ} \mathrm{C}<\right.$ mean daily temperature $<20^{\circ} \mathrm{C}$ ). We estimated that LAI before thinning was 8 with $90 \%$ crown coverage, and after thinning about 6 with $70 \%$ crown coverage. For an overcast day, this gave a reduction of $8 \%$ in tree canopy photosynthesis accompanied by an increase of $16 \%$ in ground-vegetation photosynthesis, rendering a mere $3.4 \%$ reduction in total GPP (Figure 6). During a clear day, the difference in tree canopy photosynthesis was the same, but the ground vegetation did not respond as strongly, increasing the total reduction to $5.5 \%$.

[31] Figure 7 shows temporal comparison for the size dependence of particle $v_{\mathrm{d}}$. The curves represent $v_{\mathrm{d}, \mathrm{p}}$ at the canopy top under similar meteorological conditions. The thinning appeared to reduce $v_{\mathrm{d}, \mathrm{p}}$ into the forest: The deposition curves are different at a significance level of $95 \%$.

[32] Table 2 shows temporal and spatial comparison of $v_{\mathrm{d}}$ for particles with diameter of $50 \mathrm{~nm}$. Temporal comparison shows a decrease by a factor of 2.5 (with significance of $95 \%)$. Although the values representing intact areas $(30 \%$ sector in 2002, all sectors in 2001) differ from one another probably due to stand heterogeneity, the thinning evidently decreased particle deposition.

\section{Discussion}

\subsection{Water Vapor and Ozone Fluxes}

[33] According to our initial hypothesis, the decrease of foliage should have decreased $F_{\mathrm{w}}$ and $v_{\mathrm{d}, \mathrm{O} 3}$. Contrary to this, the neutrality of $g_{\mathrm{b}}$ to the thinning indicates that the canopy and ground vegetation compensated for the foliage removal. The process of dry deposition for gases and 

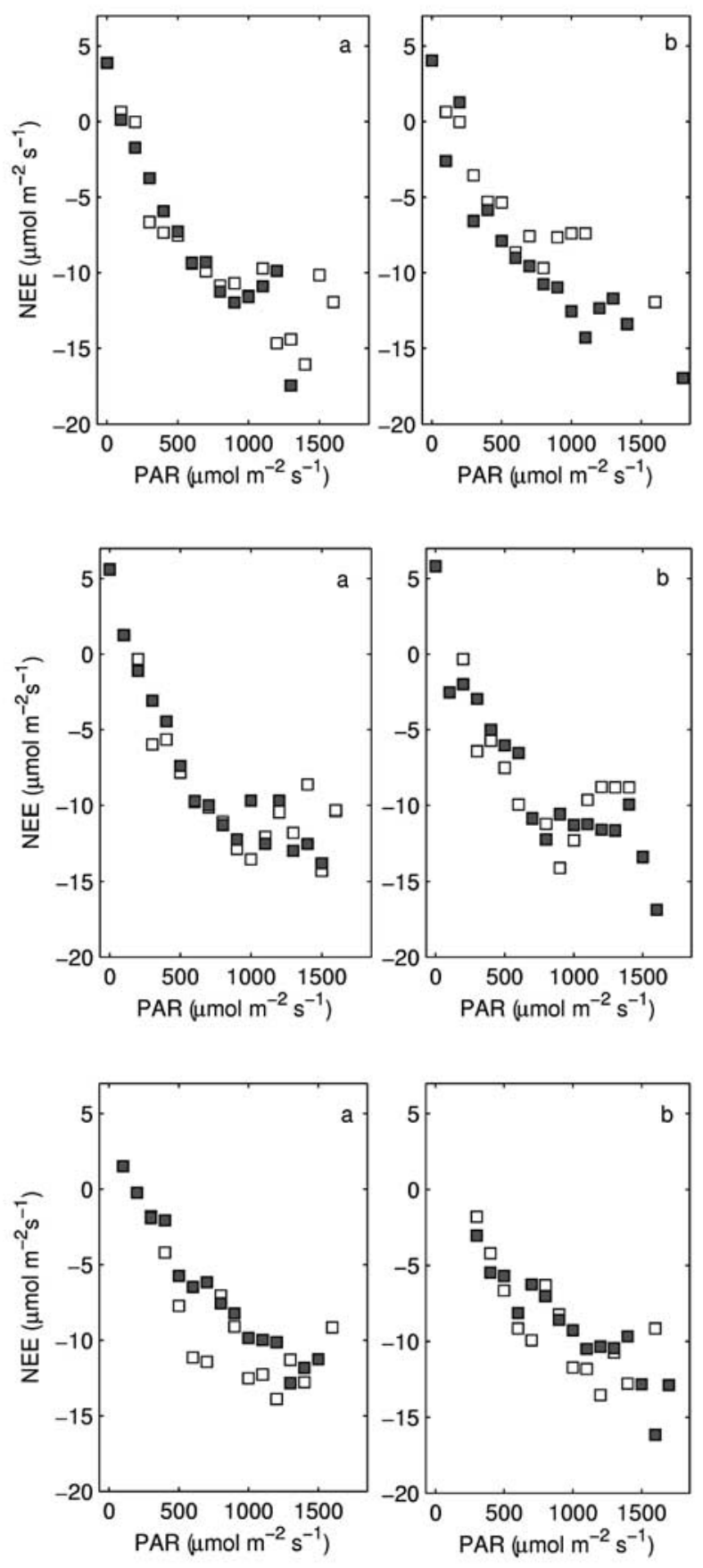

Figure 4. Comparison of the $\mathrm{CO}_{2}$ fluxes as a function of PAR for thinned and intact areas in June-July for three different air temperature ranges. Each data point represents half-hour measurements averaged over a PAR interval of $100 \mu \mathrm{mol} \mathrm{m} \mathrm{m}^{-2} \mathrm{~s}^{-1}$ (the average number of half-hour values per data point is $1-16$ ). (top) $T_{\text {air }}=14^{\circ}-17^{\circ} \mathrm{C}$; (middle) $T_{\text {air }}=17^{\circ}-20^{\circ} \mathrm{C}$; and (bottom) $T_{\text {air }}=20^{\circ}-23^{\circ} \mathrm{C}$. (a) Measured half-hour flux values in summer 2002 for the intact sectors (shaded squares, on average 127 data points) and for the thinned sectors (white squares, 116). (b) Measured flux values for the whole south-east sector in summers 1996-2001 before thinning (shaded squares, 136) and in summer 2002 after thinning (white squares, 105). particles is generally represented as consisting of three steps: aerodynamic transport through the atmospheric surface layer to the vicinity of the surface, molecular transfer across the quasi-laminar sublayer to the surface itself, and uptake at the surface [Seinfeld and Pandis, 1998]. Many gaseous compounds enter plants through stomata and, to a lesser extent, through the cuticle or are destroyed by surface reactions. The aerial transport depends on friction velocity and on the roughness of the surface, which are both modified by thinning to some extent. The transport rate through the stomata and cuticle depends on the leaf area index (LAI), which thinning affects directly. The process of transpiration is similar, water vapor being transported in the opposite direction from stomata (and to a much lesser extent through cuticle) to the atmosphere. The neutrality of transpiration and $\mathrm{O}_{3}$ deposition to the thinning (Figure 3) shows that these processes cannot be explained simply in terms of the amount of foliage. The amount of available energy for total evapo-transpiration after the thinning remained close to pre-thinning conditions, since the changes in the net radiation and sensible heat fluxes during the growing season were marginal (not shown). As a likely consequence, the total transpiration rate of the ecosystem remained at the same level, but that of individual plants was enhanced: With less competition, trees and ground vegetation could afford to transpire with a higher rate. Furthermore, ground-vegetation transpiration at the site increases linearly with increasing transmitted PAR (up to $200 \mu \mathrm{mol} \mathrm{m} \mathrm{m}^{-2} \mathrm{~s}^{-1}$ ) [Sevanto et al., 2001]. The larger stomatal apertures of ground-vegetation may explain the neutrality of $\mathrm{O}_{3}$ deposition.

\subsection{Carbon Dioxide Flux}

[34] On the basis of our initial hypothesis, we also expected that the thinning would lead to a reduction in the net uptake of $\mathrm{CO}_{2}$. However, the neutrality of NEE to the thinning suggests that respiration components increased/ decreased by about the same amount as assimilation did or that respiration and photosynthesis rates remained unaltered. In contrast to $\mathrm{O}_{3}$ and water vapor exchange, which are mainly governed by the amount of foliage, the exchange of $\mathrm{CO}_{2}$ is the small difference between uptake by vegetation and emission by soil. Both of these processes are presumably affected by thinning.

[35] The decrease in the canopy photosynthesis was significantly smaller (of the order of $10 \%$ according to our model predictions) than the actual decrease in LAI (Figure 6). At the same time, assimilation by ground vegetation may have increased by almost $20 \%$ under overcast conditions. As a result, the total reduction of the whole ecosystem GPP was estimated to be only $5 \%$ or less. Thus the ground assimilation is likely to have canceled out the reduction in canopy assimilation at least within the precision of our measurement.

[36] Up to 1 year after the thinning, the decomposition of dead fine roots and needles is a major new source of carbon. On the basis of the reduction in tree basal area, we estimate that the thinning resulted in an additional input of easily degradable litter from fine roots of about $52 \mathrm{~g} \mathrm{C} \mathrm{m}^{-2}$ and from needles of about $63 \mathrm{~g} \mathrm{C} \mathrm{m}^{-2}$. Together, these numbers 


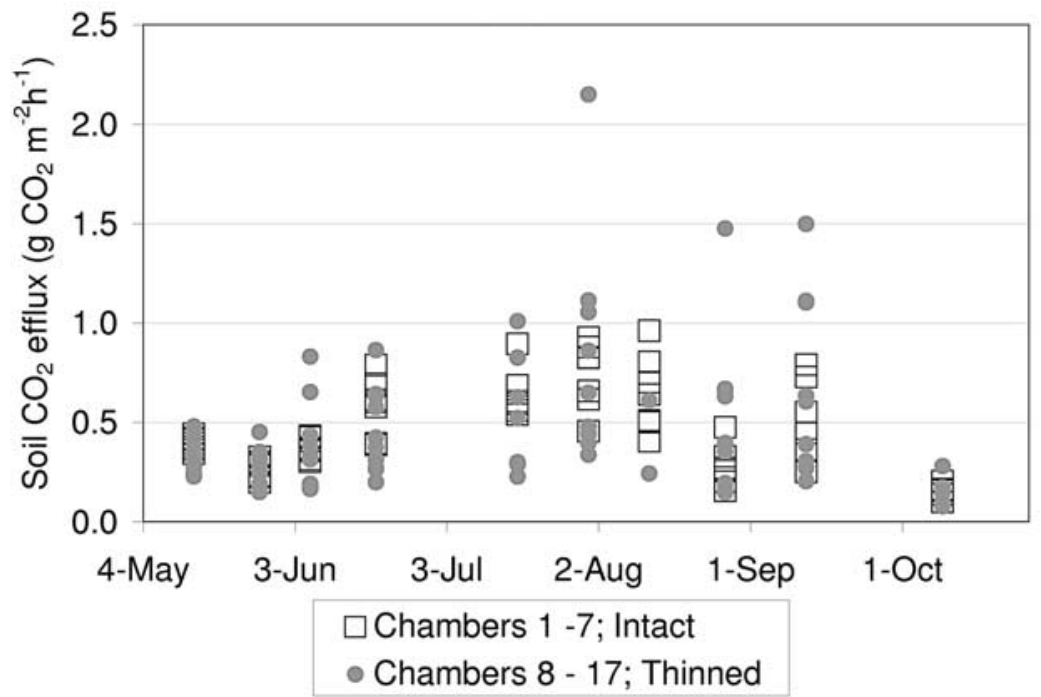

Figure 5. Soil $\mathrm{CO}_{2}$ efflux measured by soil chambers in summer 2002 in the intact (white squares) and thinned (shaded circles) areas. The distance among the chambers in each sector was 4-40 m.

roughly equal the pre-thinning annual litter production. The estimated logging waste in the form of tree tops, branches, stumps, and coarse roots was $630 \mathrm{~g} \mathrm{C} \mathrm{m}^{-2}$ after the stems, about half $\left(504 \mathrm{~g} \mathrm{C} \mathrm{m}^{-2}\right)$ of the biomass, were removed from the stand. According to these estimations and to measured mass loss coefficients [Hyvönen et al., 2000], the thinning should have caused an increase in total ecosystem respiration (TER) of $40-50 \mathrm{~g} \mathrm{C} \mathrm{m}^{-2} \mathrm{yr}^{-1}$ in the first year (First Estimate). Similarly, the model YASSO (Jari Liski, personal communication, 2003) [see also Karjalainen et al., 2002; Masera et al., 2003; Hynynen et al., 2005] gave an increase in heterotrophic soil respiration $\left(R_{\mathrm{h}}\right)$ of less than
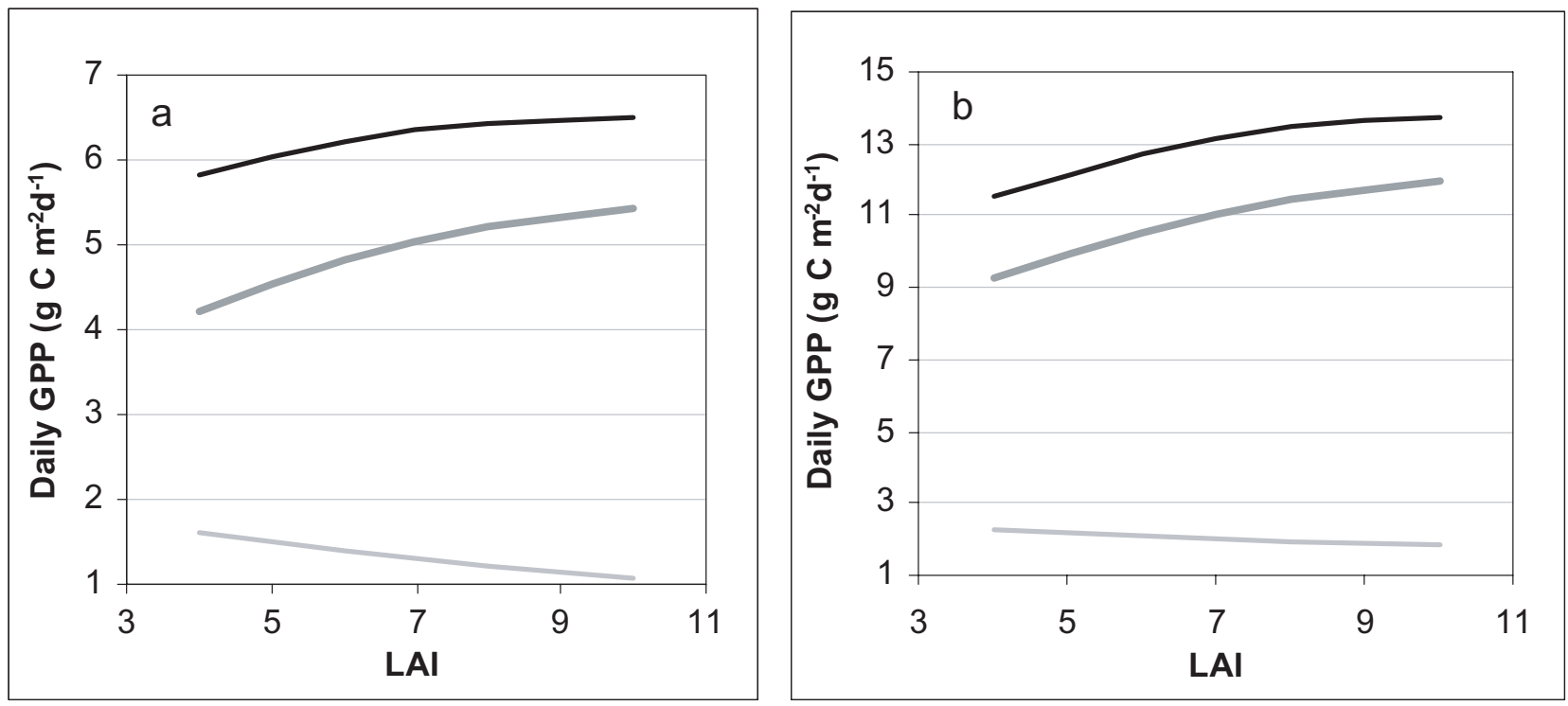

Figure 6. Model predictions for daily GPP as a function of canopy LAI, separately for groundvegetation (bottom curve) and canopy (middle curve) and for their sum (top curve). (a) Overcast day. (b) Clear day. 


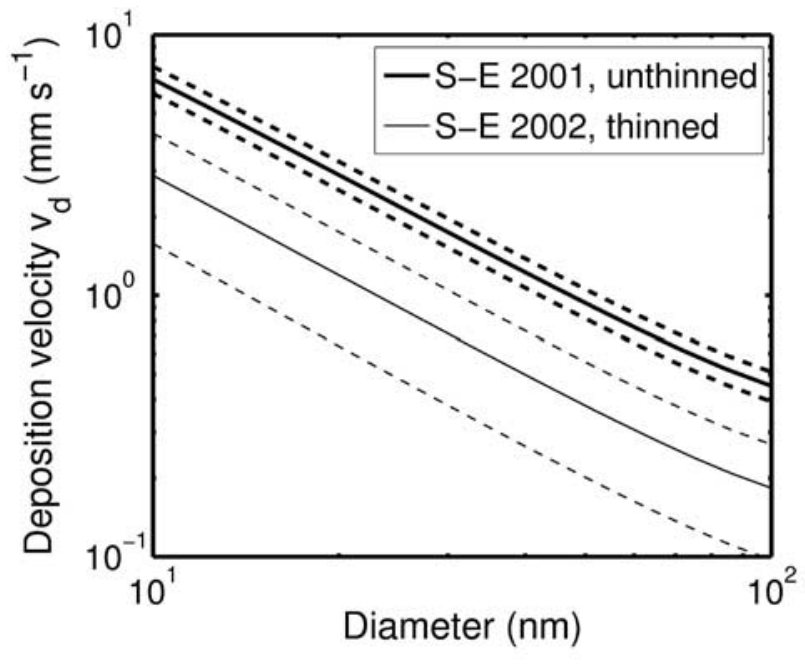

Figure 7. Temporal comparison of particle deposition: particle $v_{\mathrm{d}}$ for the $60 \%$ sectors before (unthinned) and after (thinned) the thinning for particles with diameters of 10 to $100 \mathrm{~nm}$. Dashed lines show error intervals corresponding to \pm 2 standard deviations. Deposition curves presented in the figure are based on model runs at friction velocity of $0.4 \mathrm{~m} \mathrm{~s}^{-1}$ and wind speed (at the observation level) of $2.4 \mathrm{~m} \mathrm{~s}^{-1}$, neutral conditions. EC measurements used as input for the model were obtained under near-neutral and unstable conditions, $\mathrm{RH}<90 \%$.

$10 \%$ immediately after a similar thinning for the same stand. Given that the annual soil respiration $\left(R_{\mathrm{S}}\right)$ in Hyytiälä is about $900 \mathrm{~g} \mathrm{C} \mathrm{m}^{-2} \mathrm{yr}^{-1}$ [Pumpanen et al., 2003] and assuming that half of it is heterotrophic [Högberg et al., 2001], this would equal less than $45 \mathrm{~g} \mathrm{C} \mathrm{m}^{-2} \mathrm{yr}^{-1}$ (Second Estimate). In other words, two independent estimates (First and Second) give a similar increase in TER. In the absence of compensating mechanisms, this increase in $R_{\mathrm{S}}$ should clearly decrease NEE, which is annually about $-200 \mathrm{~g} \mathrm{C} \mathrm{m}^{-2} \mathrm{yr}^{-1}$ [Suni et al., 2003]. However, assimilation and $R_{\mathrm{S}}$ in forests are strongly coupled, and any changes in the aboveground processes are reflected in the soil with variable delays. About half of $R_{\mathrm{s}}$ in a forest has been observed to derive from the current year's photosynthesis of trees [Högberg et al., 2001]. As the thinning decreased the net production, it also most likely decreased the root respiration $\left(R_{\mathrm{r}}\right)$ rate, which may have compensated for the increased $R_{\mathrm{h}}$. Let us assume that a decrease in production $(10 \%)$ results in an equal decrease in $R_{\mathrm{r}}$. This would mean a decrease of about $5 \%$ in $R_{\mathrm{s}}$ which, when combined with a decrease in aboveground autotrophic respiration, about cancels out the expected increase in $R_{\mathrm{h}}$ and leads to the short-term neutrality of TER to thinning. This anticipated 5\% decrease in $R_{\mathrm{s}}$ was not observed in our chamber measurements of the sum of soil $\mathrm{CO}_{2}$ efflux and the dark respiration rate of forest floor vegetation: We detected no drastic difference between the pre- and postthinning values, and any alterations fell within normal spatial and temporal variation at least within the precision of our measurement (Figure 5). Altogether, increases in ground-vegetation photosynthesis and decreases in above- ground and belowground autotrophic respiration seem to compensate for the opposite changes in both $R_{\mathrm{h}}$ and canopy GPP. Consequently, NEE is largely unaffected by thinning (Figure 4), but it is worth noting that our results represent a certain LAI change in a certain type of forest, although these conditions are fairly typical in managed forests in Finland. With a different initial LAI at a site with different ground vegetation and understorey components and different soil characteristics, the results could be different. Scott et al. [2004] found that NEE declined following the harvest of a coniferous stand by $18 \%$, when LAI changed by $40 \%$ from 3.5 to 2.1. Soil respiration declined slightly, but nonsignificantly. These results are in accordance with the model predictions and measurements in this study (see Figures 5 and 6).

\subsection{Aerosol Particle Fluxes}

[37] For particle deposition, our initial hypothesis appeared to be correct: The thinning did reduce $v_{\mathrm{d}, \mathrm{p}}$. In contrast to gases, the deposition of which largely depends on the access of the gas to the stomata, i.e., to the reaction sites within the plant, aerosol particles simply adhere to the surface. Their deposition is more sensitive to the actual amount of foliage: The smaller the amount, the larger the canopy resistance. In general, dry deposition of aerosol particles depends strongly on particle size but also on the collecting properties of the surface and on turbulence (proportionally to friction velocity) and atmospheric stability [e.g., Gallagher et al., 1997].

[38] Forests represent a surface that is aerodynamically very rough. In addition, the vertical structure of the canopy and the properties of the wind field inside canopy have a strong effect on particle deposition. Therefore thinning or seasonal variation in LAI should affect particle $v_{\mathrm{d}}$ at a given site. The leaf area forms a surface for aerosol deposition, and therefore a smaller leaf area density has a suppressing effect on $v_{\mathrm{d}, \mathrm{p}}$. On the other hand, reducing the leaf surface area (thinning) influences the roughness of the forest and allows higher wind speed and turbulence to develop inside the crown space, thus affecting $v_{\mathrm{d}, \mathrm{p}}$ via decreased aerodynamic resistance as well as via boundary layer resistance over leaf surfaces. Thus these two mechanisms have competing effects on particle $v_{\mathrm{d}, \mathrm{p}}$.

[39] According to Slinn [1982], the canopy resistance increases because leaf area decreases, and their relatively

Table 2. Deposition Velocities $v_{d}$ for Particles $50 \mathrm{~nm}$ in Diameter ${ }^{\mathrm{a}}$

\begin{tabular}{lccc}
\hline & $v_{d}, \mathrm{~mm} \mathrm{~s}^{-1}$ & 2 s.e., $\mathrm{mm} \mathrm{s}^{-1}$ & $N$ \\
\hline $2001,60 \%$ intact & 0.89 & 0.12 & 120 \\
$2001,30 \%$ intact & 0.60 & 0.06 & 1039 \\
$2002,60 \%$ thinned & 0.36 & 0.17 & 132 \\
$2002,30 \%$ intact & 0.48 & 0.08 & 1160 \\
\hline
\end{tabular}

${ }^{\text {a }}$ Particles are only one size, as an example. $N$ is the number of 30 -min periods used in the estimation. In the analysis, we used measurements at near-neutral and unstable conditions with $\mathrm{RH}<90 \%$, and the $v_{\mathrm{d}}$ here are presented for the friction velocity of $0.4 \mathrm{~m} \mathrm{~s}^{-1}$ and wind speed of $2.4 \mathrm{~m} \mathrm{~s}^{-1}$, neutral stratification. Here 2 s.e. stands for 2 standard errors; $60 \%$ and $30 \%$ denote wind direction sectors where after the thinning (2002), thinned areas contributed $>60 \%$ and $<30 \%$ of the flux, respectively. Before 2002 , all these sectors were intact. 
simple parameterization predicts a clear decrease in deposition velocity after thinning. The canopy resistance depends on LAI via the wind speed inside canopy, where the coefficient of exponential decrease of the speed is proportional to LAI [see also Massman, 1997]. Although thinning should cause an increase in the roughness length and a decrease in the aerodynamic resistance (depending on the ratio of the wind speed and the friction velocity), these aerodynamic changes are expected to be masked by the much stronger canopy resistance effect under most observational conditions, as in this study [see also Rannik et al., 2003].

[40] Note that the particle deposition model was here used to deduce the deposition velocities as a function of the particle size, but the simple analysis of dividing the measured particle flux by the total particle concentration would have provided a kind of total effective deposition velocity, which is obviously also reduced after thinning and which is independent of any model.

\section{Conclusions}

[41] Our initial hypothesis of thinning decreasing the surface fluxes appeared to be true only for aerosol particle deposition. Our result, the neutrality of the forest gas exchange to a normal routine thinning, touches the question of the effects and role of forest management in biogeochemical cycles. It is clear that an extreme removal of foliage (in terms of forest management) must affect all the surface fluxes, but the effects of a common routine operation, such as a first commercial thinning, on the surface fluxes of gaseous compounds can be minimal during the first year following thinning. In this study, we found that the thinning changed physical processes like wind speed normalized by the friction velocity, light penetration, wintertime albedo, and particle deposition, but that the trace gas net fluxes, partly biologically controlled, remained unaltered (or not measurably different) although the compartment fluxes may have changed. This neutrality is explained by the redistribution of sources and sinks among the canopy, ground vegetation, and soil. The role of ground vegetation appears to be especially important, which is emphasized also in the recent paper by Heijmans et al. [2004]. This leads us to re-evaluate the present understanding of responses of eco-physiological components to disturbances. However, current soil-vegetation-atmosphere transfer models should be able to reproduce the overall results. Multiyear multicomponent surface flux records provide a unique means to strengthen the knowledge of the fundamental components of biosphere-atmosphere exchange and removal processes of gaseous and particulate matter.

[42] Acknowledgment. We are grateful to Robert Flanagan and Ari Asmi for useful discussions and acknowledge the funding from the Academy of Finland and EU.

\section{References}

Aalto, P., et al. (2001), Physical characterization of aerosol particles during nucleation events, Tellus, Ser. B, 53, 344-358.

Aubinet, M., et al. (2000), Estimates of the annual net carbon and water exchange of forests: The EUROFLUX methodology, Adv. Ecol. Res., 30, $113-175$.
Aussenac, G., and A. Granier (1987), Effects of thinning on water stress and growth in Douglas-fir, Can. J. For. Res., 18, 100-105.

Baldocchi, D. D. (2003), Assessing the eddy covariance technique for evaluating carbon dioxide exchange rates of ecosystems: Past, present and future, Global Change Biol., 9, 479-492.

Black, T. A., C. S. Tan, and J. U. Nnyamah (1980), Transpiration rate of Douglas fir trees in thinned and intact stands, Can. J. Soil. Sci., 60, 625631.

Breda, N., A. Granier, and G. Aussenac (1995), Effects of thinning on soil and tree water relations, transpiration and growth in an oak forest (Quercus petraes (Matt.) Liebl.), Tree Physiol., 15, 295-306.

Buzorius, G. (2000), Variation of aerosol concentration in ambient air, Ph.D. thesis, Dep. of Phys. Sci., Univ. of Helsinki, Helsinki, Finland.

Buzorius, G., Ü. Rannik, J. M. Mäkelä, T. Vesala, and M. Kulmala (1998), Vertical aerosol particle fluxes measured by eddy covariance technique using condensational particle counter, J. Aerosol. Sci., 29, 157-171.

Buzorius, G., Ü. Rannik, J. M. Mäkelä, P. Keronen, T. Vesala, and M. Kulmala (2000), Vertical aerosol fluxes measured by the eddy covariance method and deposition of nucleation mode particles above a Scots pine forest in southern Finland, J. Geophys. Res., 105, 19,905$19,916$.

Cajander, A. K. (1909), Ueber Waldtypen, Acta For. Fenn., 1(1), 1-176.

Courbaud, B. (2002), Comparing light interception with stand basal area for predicting tree growth, Tree Physiol., 20, 407-414.

Forestry Development Centre Tapio (2001), Guidelines for Good Forest Management (in Finnish), Libris Oy, Helsinki, Finland.

Gallagher, M. W., K. M. Beswick, J. Duyzer, H. Westrate, T. W. Choularton, and P. Hummelshoj (1997), Measurements of aerosol fluxes to Speulder forest using a micrometeorological technique, Atmos. Environ., 31, 359373.

Gendron, F., C. Messier, and P. G. Comeau (1998), Comparison of various methods for estimating the mean growing season percent photosynthetic photon flux density in forests, Agric. For. Meteorol., 92, 55-70.

Heijmans, M. M. P. D., W. J. Arp, and W. S. Stuart III (2004), Carbon dioxide and water vapor exchange from understory species in boreal forest, Agric. For. Meteorol., 123, 135-147.

Högberg, P., A. Nordgren, N. Buchmann, A. F. S. Taylor, A. Ekblad, M. N. Högberg, G. Nyberg, M. Ottosson-Löfvenius, and D. J. Read (2001), Large-scale forest girdling shows that current photosynthesis drives soil respiration, Nature, 411, 789-792.

Hynynen, J., A. Ahtikoski, J. Siitonen, R. Sievänen, and J. Liski (2005), Applying the MOTTI simulator to analyze the effects of alternative management schedules on timber and non-timber production, For. Ecol. Manage., in press.

Hyvönen, R., B. A. Olsson, H. Lundkvist, and H. Staaf (2000), Decomposition and nutrient release from Picea abies (L.) Karst. and Pinus sylvestris L. logging residues, For. Ecol. Manage., 126, 97-112.

Ilvesniemi, H., and C. Liu (2001), Biomass distribution in a young Scots pine stand, Boreal Environ. Res., 6, 3-8.

Karjalainen, T., A. Pussinen, J. Liski, G.-J. Nabuurs, M. Erhard, T. Eggers, M. Sonntag, and F. Mohren (2002), An approach towards an estimate of the impact of forest management and climate change on the European forest sector carbon budget: Germany as a case study, For. Ecol. Manage., 162, $87-103$.

Kimmins, H. (1992), Balancing Act: Environmental Issues in Forestry, UBC Press, Vancouver, B.C., Canada.

Mäkelä, A., and P. Vanninen (1998), Impact of size and competition on tree form and distribution of above-ground biomass in Scots pine, Can. J. For. Res., 28, 216-227.

Markkanen, T., Ü. Rannik, B. Marcolla, A. Cescatti, and T. Vesala (2003), Footprints and fetches for fluxes over forest canopies with varying structure and density, Boundary Layer Meteorol., 106, 437-459.

Marklund, L. G. (1988), Biomass functions for pine, spruce and birch in Sweden (in Swedish), Rep. 45, Sveriges Lantbruksuniv., Inst. för Skogstaxering, Uppsala, Sweden.

Masera, O. R., J. Garza-Caligaris, M. Kanninen, T. Karjalainen, J. Liski, G. J. Nabuurs, A. Pussinen, B. H. J. de Jong, and G. M. J. Mohren (2003), Modelling carbon sequestration in afforestation, agroforestry and forest management projects: The CO2FIX V.2 approach, Ecol. Modell., 164, 177-199.

Massman, W. J. (1997), An analytical one-dimensional model of momentum transfer by vegetation of arbitrary structure, Boundary Layer Meteorol., 83, 407-421.

McNaughton, K. G., and P. G. Jarvis (1983), Predicting effects of vegetation changes on transpiration and evaporation, in Water Deficits and Plant Growth, vol. VII, pp. 1-47, Elsevier, New York.

Medhurst, J. L., M. Battaglia, and C. L. Beadle (2002), Measured and predicted changes in tree and stand water use following high-intensity 
thinning of an 8-year-old Eucalyptus nitens plantation, Tree Physiol., 22, $775-784$.

Mölder, M., L. Klemedtsson, and A. Lindroth (2004), Turbulence characteristics and dispersion in a forest-Tests of Thomson's random-flight model, Agric. For. Meteorol., 127, 203-222.

Oker-Blom, P., T. Pukkala, and T. Kuuluvainen (1989), Relationships between radiation interception and photosynthesis in forest canopiesEffects of stand structure and latitude, Ecol. Modell., 49, 73-87.

Palmroth, S. (2001), Evaluation of the importance of acclimation of needle structure, photosynthesis, and respiration to available photosynthetically active radiation in a Scots pine canopy, Can. J. For. Res., 31, 1235-1243.

Palva, L., et al. (2001), Tree scale distributed multipoint measuring system of photosynthetically active radiation, Agric. For. Meteorol., 106, 71-80.

Peltola, A. (Ed.) (2001), Yearbook of Forest Statistics (in Finnish), Finn. For. Res. Inst., Vammala, Finland.

Piene, H., and K. Van Cleve (1978), Weight loss of litter and cellulose bags in a thinned white spruce forest in interior Alaska, Can. J. For. Res., 8, $42-46$.

Pumpanen, J., H. Ilvesniemi, M. Perämäki, and P. Hari (2003), Seasonal patterns of soil $\mathrm{CO}_{2}$ and soil air $\mathrm{CO}_{2}$ concentration in a Scots pine forest: Comparison of two chamber techniques, Global Change Biol., 9, 371382.

Rannik, Ü. (1998), Turbulent atmosphere: Vertical fluxes above a forest and particle growth, Ph.D. thesis, Dep. of Phys., Univ. of Helsinki, Helsinki, Finland.

Rannik, Ü., M. Aubinet, O. Kurbanmuradov, K. K. Sabelfeld, T. Markkanen, and T. Vesala (2000a), Footprint analysis for measurements over a heterogeneous forest, Boundary Layer Meteorol., 97, 137-166.

Rannik, Ü., T. Petäjä, G. Buzorius, P. Aalto, T. Vesala, and M. Kulmala (2000b), Deposition velocities of nucleation mode particles into a Scots pine forest, Environ. Chem. Phys., 22, 97-102.

Rannik, Ü., P. Aalto, P. Keronen, T. Vesala, and M. Kulmala (2003), Interpretation of aerosol particle fluxes over a pine forest: Dry deposition and random errors, J. Geophys Res., 108(D17), 4544, doi:10.1029/ 2003JD003542.

Raupach, M. R., and A. S. Thom (1981), Turbulence in and above plant canopies, Аnnu. Rev. Fluid Mech., 13, 97-129.

Schade, G. W., and A. H. Goldstein (2003), Increase of monoterpene emissions from a pine plantation as a result of mechanical disturbances, Geophys. Res. Lett., 30(7), 1380, doi:10.1029/2002GL016138.

Scott, N. A., C. A. Rodrigues, H. Hughes, J. T. Lee, E. A. Davidson, D. B. Dail, P. Malerba, and D. Y. Hollinger (2004), Changes in carbon storage and net carbon exchange one year after an initial shelterwood harvest at Howland Forest, ME, Environ. Manage., 33, Suppl. 1, S9-S22.

Seinfeld, J. H., and S. N. Pandis (1998), Atmospheric Chemistry and Physics: From Air Pollution to Climate Change, John Wiley, Hoboken, N. J.

Sevanto, S., T. Vesala, M. Perämäki, J. Pumpanen, H. Ilvesniemi, and E. Nikinmaa (2001), Xylem diameter changes as an indicator of standlevel evapo-transpiration, Boreal Environ. Res., 6, 45-52.

Sevola, Y. (Ed.) (2003), Forest Finland in brief, report, 48 pp., Finn. For. Res. Inst., Helsinki. (Available at http://www.metla.fi/metinfo/tilasto/ julkaisut/muut/brief2003.pdf)
Slinn, W. G. N. (1982), Predictions of particle deposition to vegetative canopies, Atmos. Environ., 16, 1785-1794.

Sogachev, A., and J. Lloyd (2004), Using a one-and-a-half order closure model of the atmospheric boundary layer for surface flux footprint estimation, Boundary Layer Meteorol., 112, 467-502.

Suni, T., J. Rinne, A. Reissel, N. Altimir, P. Keronen, Ü. Rannik, M. Dal Maso, M. Kulmala, and T. Vesala (2003), Long-term measurements of surface fluxes above a Scots pine forest in Hyytiälä, southern Finland, 1996-2001, Boreal Environ. Res., 8, 287-301.

Thomson, D. J. (1987), Criteria for the selection of stochastic models of particle trajectories in turbulent flows, J. Fluid Mech., 180, 529556.

Valkeapää, A. (2001), The accuracy of different destructive estimation methods of foliage area (in Finnish), M.Sc. thesis, Dep. of Stat., Univ. of Helsinki, Helsinki.

Van Wijk, M. T., S. C. Dekker, W. Bouten, W. Kohsiek, and G. M. J. Mohren (2001), Simulation of carbon and water budgets of a Douglasfir forest, For. Ecol. Manage., 145, 229-241.

Vesala, T., et al. (1998), Long-term field measurements of atmospheresurface interactions in boreal forest combining forest ecology, micrometeorology, aerosol physics and atmospheric chemistry, Trends Heat Mass Momentum Transfer, 4, 17-35.

Vesala, T., T. Markkanen, L. Palva, E. Siivola, S. Palmroth, and P. Hari (2000), Effect of variations of PAR on $\mathrm{CO}_{2}$ exchange estimation for Scots pine, Agric. For. Meteorol., 100, 337-347.

Waring, R. H., and S. W. Running (1998), Forest Ecosystems: Analysis at Multiple Scales, 2nd ed., Elsevier, New York.

Wesely, M. L., and B. B. Hicks (2000), A review of the current status of knowledge on dry deposition, Atmos. Environ., 34, 2261-2282.

Whitehead, D., P. G. Jarvis, and R. H. Waring (1984), Stomatal conductance, transpiration, and resistance to water uptake in a Pinus sylvestris spacing experiment, Can. J. For. Res., 14, 692-700.

N. Altimir, P. Hari, P. Kolari, L. Kulmala, A. Mäkelä, E. Nikinmaa, and J. Pumpanen, Department of Forest Ecology, P.O. Box 27, University of Helsinki, Helsinki, FIN-00014 Finland.

F. Berninger, Département des Sciences Biologiques, Université du Québec à Montréal, CP 8888 succ. Centre Ville, Montreal, QC, Canada.

T. Grönholm, P. Keronen, M. Kulmala, T. Markkanen, Ü. Rannik, S. Smolander, T. Suni, and T. Vesala, Department of Physical Sciences, P.O. Box 64, University of Helsinki, Helsinki, FIN-00014 Finland. (timo.vesala@helsinki.fi)

H. Ilvesniemi and R. Ojansuu, Vantaa Research Centre, Finnish Forest Research Institute, P.O. Box 18, Vantaa, FIN-01301 Finland.

J. Levula and A. Uotila, Hyytiälä Forestry Field Station, University of Helsinki, Hyytiäläntie 124, Helsinki, FIN-35500 Finland.

S. Sevanto, Harvard University, 16 Divinity Avenue, Biological Laboratory, Cambridge, MA 02138, USA. 


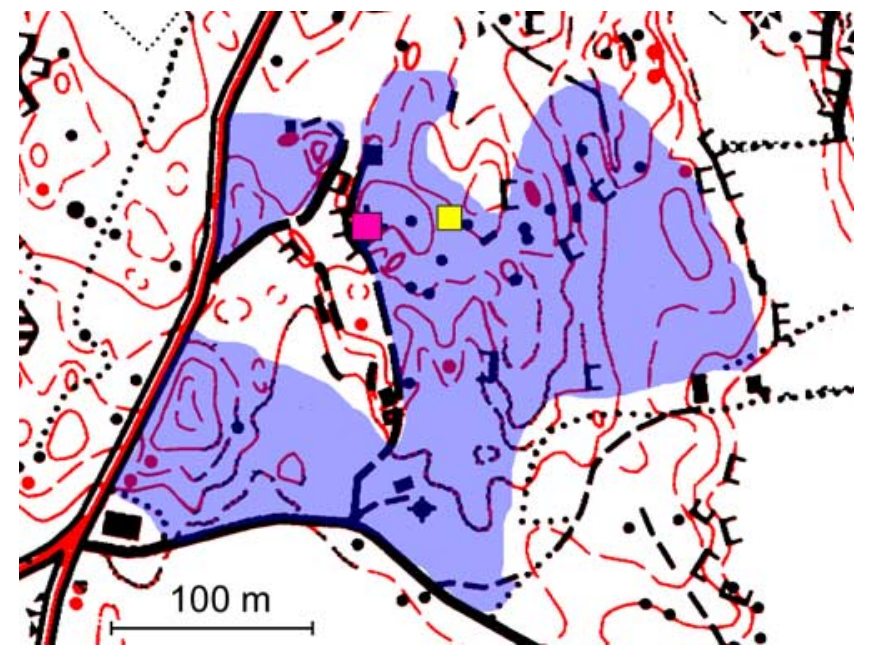

Figure 1. Map of the site. Tower 1 (red square) was installed in April 1996 and measures fluxes of water vapor, $\mathrm{CO}_{2}$, and aerosol particles. Tower 2 (yellow square) was installed in August 2001 and measures fluxes of water vapor, $\mathrm{CO}_{2}$, and $\mathrm{O}_{3}$. The blue areas were thinned January-March 2002. 